\title{
Utilizing the Balanced Scorecard in Ranch Management: Cattle Production Systems Perspective
}

\section{By H. H. "Trey" Patterson and Clinton Richardson}

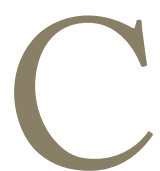

omplexity in the ranching business makes it difficult for mangers to ascertain whether applied strategies are successful in helping the business reach its goals. The time gap between cause and effect in biological systems can cause a lag in feedback that leads to frustration and hindered decision making. The Balanced Scorecard (BSC) gives managers a tool for strategy development and feedback for appropriate evaluation of long-term business success. ${ }^{1}$ The objective of this paper is to give an example of how to develop the livestock production perspective of the Balanced Scorecard by giving strategies for success and the associated metrics to measure success. Although strategies will vary by ranch, we will illustrate and explain some key strategies to consider in generating in developing cattle production systems.

The first step in developing a Balanced Scorecard is defining the vision for the business. A vision statement will be different for each ranch, but should contain aspects of profitability and ranch sustainability.

Long-term outcomes of profitable cattle production systems likely include:

1) Low overhead costs

2) Limited reliance on labor

3) Low reliance on harvested and purchased feed

4) Good productivity

5) High revenue per head

The strategies we discuss focus on achieving these outcomes from the perspective of livestock production as part of meeting the overall vision. A rancher needs to be aware that there is an inherent relationship between costs and revenues.

This article has been peer reviewed.
For example, if you do not have a system that is low cost (outcomes 1, 2, and 3 above), then you must have high production and revenue (outcomes 4 and 5). A rancher needs to work on both sides of the equation simultaneously. We have found, however, that in many ranch operations, the highest leverage lies in attacking the cost side of the equation.

\section{Constraints}

Every ranch system operates under a unique set of constraints. These constraints will have a profound effect on the strategy and metrics that might appear on a balanced scorecard. Some production constraints on a ranch might include context of cost, a stocking rate equal to carrying capacity, drought plan, labor, environment, market, and wildlife. Consideration of these constraints can help in managing the antagonisms that oftentimes exist between the production systems and the additional perspectives in the balanced scorecard. Appropriate production decisions can be made within the context of the entire system rather than focusing on each perspective separately. There should be clear relationships between the metrics of the production perspective and each of the other perspectives. Kaplan and Norton write that "the chain of cause-and-effect should pervade all four perspectives of the balanced scorecard." (p. 30)

\section{Strategic Planning}

Strategic planning is "...to achieve a sustainable long-term excellent fit for the farm business with its environment...." (p. 32) A review of the literature and experience has led the authors to select four strategies that will help achieve a longterm fit for a ranch. This fit is not only biological in nature but encompasses production and marketing. These four strategies are considered foundational to any ranching operation that deals with livestock production. 


\begin{tabular}{|l|l|}
\hline \multicolumn{2}{|l|}{$\begin{array}{l}\text { Table 1. Metabolizable energy requirements } \\
\text { of dry cows }\end{array}$} \\
\hline Breed cross & $\begin{array}{l}\text { Requirements, Kcal ME/kg } \\
\text { BW }^{\text {0.75 }}\end{array}$ \\
\hline Angus $\times$ Hereford & 130 \\
\hline Charolais $\times$ British & 129 \\
\hline Jersey $\times$ British & 145 \\
\hline Simmental $\times$ British & 160 \\
\hline
\end{tabular}

$\mathrm{ME}=$ metabolizable energy. $\mathrm{BW}=$ body weight.

\section{Strategy 1: Match Genetics to the Environment}

Bob Taylor said: "Profitable cattle are usually productive. Productive cattle are not always profitable." ${ }^{4}$ This is a concept that must be understood when making genetic selection decisions for the cowherd. The biological type of cattle in a production system must fit the system and environment in which they are asked to perform. Low weaning rates (or pounds weaned) per cow exposed leads to lower profitability. High expenditures to achieve good weaning rates often leads to lower profitability.

Requirements must be associated with biological type of cow, not just cow size. Milk production has a large impact on requirements, even when a cow is not lactating. Ferrell and Jenkins summarized the energy requirements of different breed crosses of dry cows on a metabolic body weight basis (Table 1). ${ }^{5}$ Simmental $\times$ British cross cattle had a higher energy requirement than Charolais $\times$ British cross per unit of metabolic bodyweight. Even if the two types of cows were the same size, the Simmental cross would have higher energy requirements. The reason is biological type of animal, including milk production, growth potential, etc. It is important to note that there are different biological types of cattle within breeds. For example, there are Angus cattle that have been selected to grow and milk more similarly to Simmental cattle than conventional Angus, and vice versa.

High maintenance cows have 1) high milk production, 2) high visceral organ weight, 3) high body lean mass, 4) low body fat, 5) high output, and 6) high input. The opposite is true for low maintenance cows. ${ }^{6}$ Jenkins illustrated this by supplying cows of different biological types varying levels of feed input (dry matter intake) over the course of a year. ${ }^{7}$ Larger, higher-output type cows had a greater weaning weight per cow exposed in a liberal feed situation than did a moderate biological type. However, when feed supply was restricted, the moderate biological type had a greater weaning wt/cow exposed than the larger type cow. In a liberal feed and/or low stress environment, heavier milking, larger cattle are more efficient; in a restricted feed or high stress environment, moderate milking and moderate sized cattle are more efficient. ${ }^{6}$ Note that the environment is not necessarily related to the part of the country. One Northern Great Plains

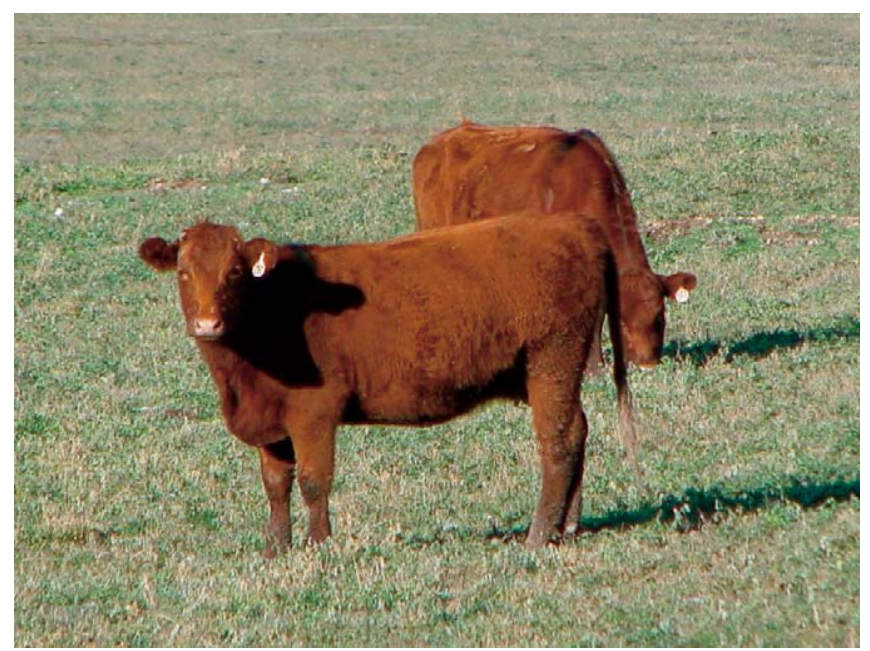

Heifers grazing farmground, Padlock Ranch, Dayton, Wyoming.

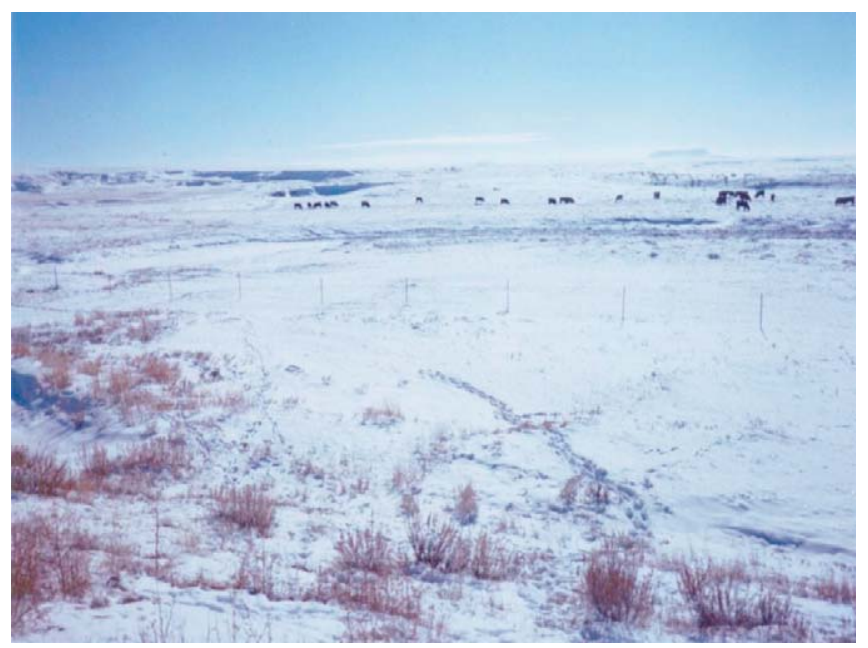

Cows grazing winter range in northern South Dakota.

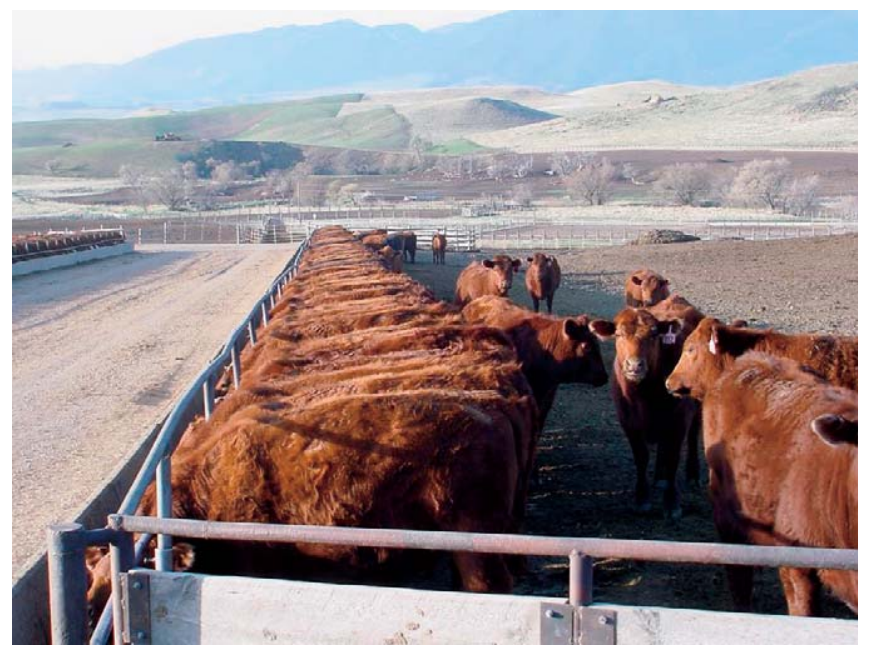

Heifers in feedlot, Padlock Ranch, Dayton, Wyoming.

rancher might strive to run cows on native range with no hay and limited supplement, whereas another might have the option to winter cows on crop aftermath and ethanol production by-products (at relatively low costs). 
Therefore, a rancher must look at the environment and system in which cows are running and evaluate the key metrics of performance in those systems. One key metric to evaluate is unit cost of production, or the cost to produce a pound of calf. You can lower unit cost of production by increasing output (pounds of calf weaned/cow exposed) or by lowering cost. If in most years unit cost of production does not allow for profit, then the biological type of cow or the system in which they are running must be re-evaluated. Examples of other key metrics to evaluate this strategy on a balanced scorecard are:

1) Pregnancy rate

2) Weaning weight/cow exposed

3) Cows bred in the first 21 days of the breeding season

4) Cow body condition score in at pregnancy testing

5) Harvested/purchased feed costs

\section{Strategy 2: Produce a Market-Targeted Animal} Producing a product that fits the particular market is important to any producer. Producers must decide "...which marketing method to use (direct negotiation with buyers, auction selling, terminal markets, forward contracts, etc.), where to sell, when to sell, and in some cases, what form of product to sell (heavy weights, light weights, at what quality grade, what frame, etc." (p. 1) It is important to understand that not all cattle will fit all markets and the type of production system used has a large impact on the marketing options. The strategies and metrics used in the BSC should be in line with the actual production potential of the herd. Therefore, a rancher needs to be able to predict how his cattle will perform. If this is unknown then one metric might be to enroll in a retained ownership alliance that generates the required information. Current production practices and genetics in the herd might preclude the qualification for branded programs. If the goal is to qualify for a particular branded program then adjustments need to be made in other aspects of the production system (i.e., genetics). The goals and metrics of this strategy can therefore have a synergistic relationship. We might choose the following metrics to measure success in the marketing strategy:

1) Market premiums received

2) Percent of cattle that qualify for a particular branded program

Each of these would be both lagging and leading indicators. The market premiums received would indicate how well our product fits the particular market. This strategy would tie into the customer service perspective of the scorecard because market premiums would also be an indicator of demand for our products.

\section{Strategy 3: Match Production System to the Environment}

The keys to matching the production system to the environment are: understanding body condition score (BCS) management, the lactation curve, and forage/feed nutrient supply.

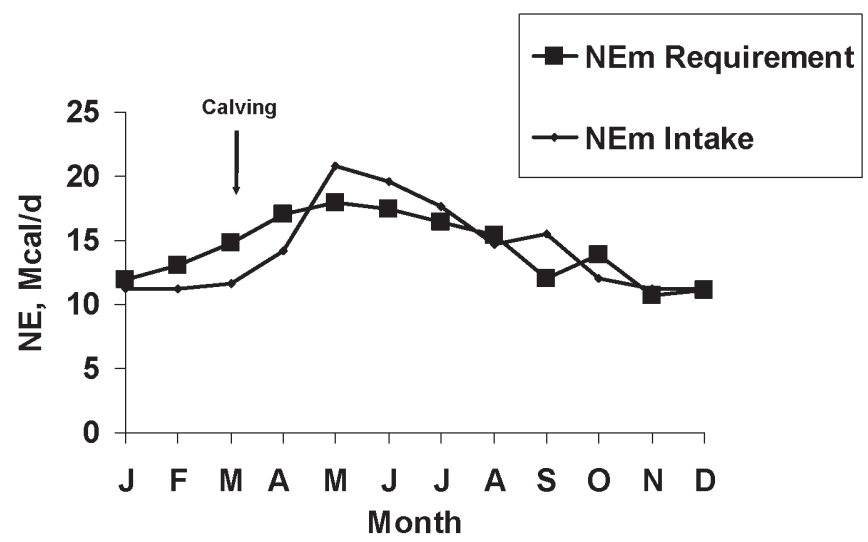

Figure 1. Net energy for maintenance (NEm) requirements and predicted NEm intake of a March-calving cow grazing rangeland in the Northern Great Plains with no supplemental feed (assume calf weaned in late October).

Richards and associates found that if cows calved at a BCS of 4 or less (1-9 scale), post partum interval (time from calving to first fertile estrus) was 12 days longer than if they calved at a body condition score of 4 or lower. ${ }^{9}$ Short concluded that a BCS at calving less than 5 in beef cattle would result in lower fertility unless an abundance of nutrients were present post-calving. ${ }^{10}$ Many have interpreted such data as meaning cows need to be in body condition of 5 or greater throughout the production year. Certainly, it is ideal to have cattle in moderate condition year-round, because there is less risk associated with varying environmental conditions, etc. However, cows can be thinner than a BCS 5 during the production year and still rebreed, given that body condition score at calving is indeed moderate and/or nutrient availability during and after calving is ample. Body condition score at calving needs to be looked at both as a leading and lagging indicator. For example, a low BCS one year might mean lower pregnancy rates during that year (lagging because it could be too late to respond), but it also might mean impaired reproduction in the following production year (leading indicator). Thin cows can become pregnant in year one of being thin at calving, but they might be bred later in the breeding season. ${ }^{11}$ If they are thin in a consecutive year, they might experience reproductive failure. We often emphasize $\mathrm{BCS}$ in the fall for spring-calving cows because it gives an indication of how much feed needs to be given during the winter to result in an adequate BCS at calving time. As we will discuss, this is dependent on the time of calving and the system in which the cattle are managed.

Forage nutrient supply from native grasses varies across locations, depending on temperature, moisture, and forage types. In the Northern Great Plains, the supply of nutrients from native rangeland begins to rise in April or May with spring growth of cool-season plants and usually peaks sometime in June. The period of high quality in June can be extended into early July as warm-season plants grow and produce nutrients. Certainly this pattern is different in southern 


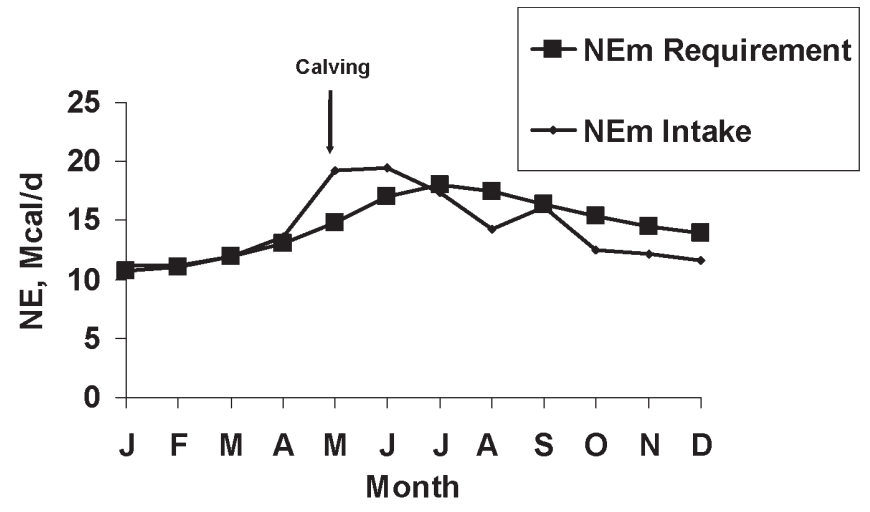

Figure 2. Net energy for maintenance (NEm) requirements and predicted NEm intake of a May-calving cow grazing rangeland in the Northern Great Plains with no supplemental feed (assume calf weaned in late November).

regions of the United States. Ranchers can consult local Extension or Experiment Stations for data relative to nutrient supply in a given area. It is important to note that nutrient supply can be manipulated to some degree by using annual forages, crops, and crop residues.

Working in the Sandhills of Nebraska, Adams and associates concluded that systems that have less reliance on harvested and purchased feeds have more potential to be profitable. ${ }^{12}$ Although not all-inclusive, this is a concept that holds true for most production systems. Therefore, it is important to match requirements with supply of nutrients from forages. Given a certain biological type of animal, the key to accomplishing this match is manipulating the timing of lactation, or time of calving and weaning.

Cattle requirements begin to increase during the second trimester of pregnancy and continue to increase until approximately 2 months after calving, or peak lactation. Requirements then decline gradually until weaning and pick back up with the next pregnancy. The timing in which calving occurs and lactation ends markedly affects the match between requirements and nutrient supply. Figure 1 shows the net energy for maintenance $(\mathrm{NEm})$ requirements and predicted intake (supply) of a March-calving cow using data typical of native rangeland in the Northern Great Plains. Note the mismatch between energy requirements and intake from January through April. Many ranchers feed significant amounts of harvested and purchased feeds during this period to avoid low body condition at calving. If the calving season is shifted to May (Fig. 2), note that requirements equal intake from January through April. In addition, energy intake is greater than requirements just prior to and after calving. The significance of this is that thin cows have an opportunity to put on condition prior to calving if they are too thin going into the spring. Certainly there is annual variation in nutrient intake, but the point is that a May-calving system results in the need for less harvested and purchased feedstuff in this scenario. The May-calving system can result in requirements being greater than nutrient intake during the fall of the year, which can cause cows to lose condition going into the winter. In some years this can be mediated through early weaning (data in Fig. 2 are with assumption that weaning would occur in late November), supplementation, or reliance on an excess of energy in the spring to make up for low condition.

Working in the Sandhills of Nebraska, Clark and associates conducted a 5-year study comparing March to June calving. Researchers reported that cows in the June calving season were fed an average of 227 pounds per head of hay each year compared to 3,947 pounds of hay per year for March-calving cows. The authors attributed the reduction in hay feeding to matching cow requirements to nutrient supply. Included in this system was the period of time before calving when intake was greater than requirements. Pregnancy and weaning rates were not different between March- and June-calving cows, but June-born calves were approximately 60 pounds lighter at weaning (same age) than the March-born calves. The market prices were higher for calves and cull cows when June-born calves were weaned in January than when March-born calves were weaned in October. The result was $\$ 37 /$ head advantage in revenue for June-born calves compared to March-born calves. ${ }^{13}$ Calving in the warmer conditions can also reduce labor needs associated with calving.

Time of weaning is another tool for managing lactation. Landblom and associates showed that weaning in August versus November improved cow body condition going into the winter and resulted in a $27 \%$ reduction in forage utilization from August to November. ${ }^{14}$

In developing a Balanced Scorecard for an operation, the environment, feed availability, and feed quality must be considered. In addition, many other factors are affected by decisions related to time of calving and weaning, including labor needs, marketing, range management, and others. That is where the Balanced Scorecard fits in. Metrics to consider in evaluating this strategy include:

1) Harvested/purchased feed costs

2) Days fed hay during the production year

3) Unit cost of production

4) Cow/man ratio

5) Body condition score at calving

\section{Strategy 4: Stocking Rate Includes Mix of Livestock Classes}

Running a mixture of livestock classes, which might include cow-calf pairs and stockers, can be an effective strategy for several reasons. First, current and future stocking rates can be adjusted based on available forage and precipitation. This adjustment allows stocking rate to be matched with the actual carrying capacity. ${ }^{15}$ Second, running a mixture of livestock classes provides flexibility in marketing. Yearlings or cull animals could be grazed and marketed to take advantage of market trends and can help to balance cash flows throughout the year.

Cull animals should not be ignored in the development of this strategy. As much as $16 \%$ of gross income on many 
Table 2. Example strategies and corresponding metrics for the livestock production perspective of the Balanced Scorecard for a ranch
1. Match genetics to the environment
- Pregnancy rate
- Weaning weight/cow exposed
- Cows bred in first 21 days of the breeding season
- Cow body condition score at pregnancy testing
- Harvested/purchased feed costs

2. Produce a market targeted animal

- Market premiums received

- Percent cattle which qualify for a particular branded program

3. Match production system to the environment

- Harvested/purchased feed costs

- Days fed hay during the production year

- Unit cost of production

- Cow/man ratio

- Body condition score at calving

4. Stocking rate includes a mix of livestock classes

- Percent pairs and percent yearlings

- Stocker gain/day

- Pregnancy rate

- Cull cow revenue

ranches comes from cull cows and bulls. ${ }^{16}$ Metrics to measure opportunities for adding value to cull cows and bulls could be included in the strategy. A proper mix of livestock classes would be a key strategy to the long-term success of the business. Each class should have specific metrics to measure success. These metrics might include:

1) Percent pairs and percent yearlings

2) Stocker gain/day

3) Pregnancy rate (cows)

4) Cull cow revenue

These metrics could be considered both leading and lagging indicators. The ability of a ranch to respond to drought and market trends in the future would be reflected in the percent pairs and percent yearlings metric. Stocker gains would be a lagging indicator of past performance. Pregnancy rate would be both a lagging and leading indicator of both past performance and could be used to predict future pounds of calf weaned and future revenues.

\section{Conclusions}

Success in the ranching industry can be measured by how well the management and work accomplished today helps to fulfill the vision of the future. The production perspective of the balanced scorecard helps ranchers to identify those processes "...critical for achieving customer and shareholder objectives." (p. 92) The purpose of this paper has been to provide an example of how a rancher might develop the livestock production perspective of the Balanced Scorecard. The fulfillment of the vision of the ranch is directly related to the effectiveness and efficiency of the production processes that occur on the ranch. The authors have identified four strategies and associated metrics that affect the future sustainability and profitability of a ranch. These strategies include match genetics to environment, produce a market targeted animal, match production systems to environment, and stocking rates includes a mix of livestock classes. Although these strategies and metrics are somewhat generic for the purposes of this paper, they should be considered foundational to any livestock production system on a ranch. A mixture of leading and lagging indicators (metrics) allows a rancher to be more proactive and less reactive in planning. For example, body condition score at calving or percent of calves qualifying for a branded program can be used to evaluate both past management decisions and predict outcomes expected in the future. Management adjustments can then be made to help close the gap between the vision and current reality.

Kaplan and Norton wrote: "In the Balanced Scorecard, the objectives and measures for the [internal-business-process perspective] are derived from explicit strategies to meet shareholder and targeted customer expectations. This sequential, top-down process will usually reveal entirely new business processes at which the organization must excel." ${ }^{2}$ (p. 93-94) The strategies and metrics developed in this paper were developed to meet both customer and shareholder expectations. The strategies and metrics will therefore flow upward through the customer and financial and lifestyle perspectives and ultimately to the vision of the ranch. In Table 2, the authors list recommended strategies and metrics for the livestock production perspective of the Balanced Scorecard.

Authors are Assistant to the CEO, Padlock Ranch, HC 64 Box 65 Ranchester, WY 82839, trey@padlockranch.com (Patterson); and Graduate Fellow, King Ranch Institute for Ranch Management, Texas AEM University-Kingsville, Kingsville, TX 78363-8202 (Richardson).

\section{References}

1. Kaplan, R. S., and D. P. Norton. January-February 1996. Using the balanced scorecard as a strategic management system. Harvard Business Review 74(1):1-11.

2. Kaplan, R. S., and D. P. Norton. 1996. The Balanced Scorecard. Boston, MA: Harvard Business School Press. 322 p.

3. Shadbolt, N., and S. Martin. Farm management in New Zealand. 2005. New York, NY: Oxford University Press. 408 p.

4. TAylor, R. A. 1994. Colorado State University. Personal Communication.

5. Ferrell, C. L., and T. G. Jenkins. 1984. Energy utilization by mature, nonpregnant, nonlactating cows of different breeds. Journal of Animal Science 58:234-243. 
6. Ritchie, H. D. 1995. The optimum cow-what criteria must she meet? In: Proceedings of the Beef Improvement Federation Annual Conference; 31 May-3 June; Sheridan, WY. p 126-141.

7. Jenkins, T. G. 1995. Performance of different biological types of cows under varying levels of feed availability. Washington State University Beef Information Day. Pullman, WA: Washington State University. 7p.

8. Rust, C. H., And D. Bailey. 1994. Beef marketing technology (Electronic). Beef Cattle Handbook. BCH-8460. p. 1

9. Richards, M. W., J. C. Spitzer, and M. B. Warner. 1986. Effect of varying levels of postpartum nutrition and body condition at calving on subsequent reproductive performance in beef cattle. Journal of Animal Science 62:300-306.

10. Short, R. E., R. A. Bellows, R. B. Staigmiller, J. G. BerarDinelli, And E. E. Custer. 1990. Physiological mechanisms controlling anestrus and infertility in postpartum beef cattle. Journal of Animal Science 68:799-816.

11. Pruitt, R. J., And P. A. Momont. 1988. Effects of body condition on reproductive performance of range beef cows. SD Beef Report. CATTLE 88-11. Brookings, SD: South Dakota State University.
12. Adams, D. C., R. T. Clark, S. A. Coady, J. B. Lamb, and M. K. Nielsen. 1994. Extended grazing systems for improving economic returns from Nebraska Sandhills cow/calf operations. Journal of Range Management 47:258-263.

13. Clark, R. T., D. C. Adams, G. Carriker, R. E. Sanberg, T. Milton, J. Musgrave, T. J. Klopfenstein, and G. P. LARDY. 1999. March vs. June calving systems: production and economic considerations. In: Proceedings of the University of Nebraska Gudmundsen Sandhills Laboratory Field Day, June 1999; Whitman, NE. 10 p.

14. Landblom, H., H. Patterson, P. Johnson, R. Gates, and S. PAisley. 2005. Effects of weaning date and retained ownership on cattle performance and forage disappearance in spring calving beef systems. Proceedings of the Western Section of the American Society of Animal Science 56:291-294.

15. Carpenter, B. B., And C. R. Hart. 1999. Livestock management during drought. College Station, TX: Texas Agriculture Extension Service. RLEM No. 2.4 p.

16. NCBA. 1999. Executive summary of the 1999 national market cow and bull quality audit. Englewood, CO: National Cattlemen's Beef Association. 15 p. 